\title{
Designing a Structure of the Modular Competence-Based Curriculum and Technologies for Its Implementation into Higher Vocational Institutions
}

\author{
Regina Gennadyevna Sakhieva ${ }^{1}$, Elmira Robertovna Khairullina ${ }^{2}$, Lyutziya Gabdulkhakovna Khisamiyeva ${ }^{2}$, \\ Nailya Shaukatovna Valeyeva ${ }^{2}$, Alfiya Rafisovna Masalimova ${ }^{3} \&$ Venera Gilmkhanovna Zakirova ${ }^{3}$ \\ ${ }^{1}$ Academy of Social Education, Tatarstan, Kazan, Isaeva Street, 12, Russian Federation \\ ${ }^{2}$ Kazan National Research Technological University, Tatarstan, Kazan, K. Marksa Street, 68, Russian \\ Federation \\ ${ }^{3}$ Kazan (Volga region) Federal University, Tatarstan, Kazan, Kremlyevskaya Street, 18, Russian Federation \\ Correspondence: Regina Gennadyevna Sakhieva, Academy of Social Education, Kazan, 420039, Russian \\ Federation. E-mail: saxievarg@mail.ru
}

Received: September 22, 2014 Accepted: October 23, 2014 Online Published: December 20, 2014

doi:10.5539/ass.v11n2p246

URL: http://dx.doi.org/10.5539/ass.v11n2p246

\begin{abstract}
The submitted article deals with the theoretic and practically-oriented aspects of planning and implementing the modular competence-based curriculum in higher professional institutions. Particularly, the authors submit the structure of the modular competence-based curricula, develop the principles of their projecting, describe the technology of introducing the modular competence-based curriculum in higher professional institutions. The developed structure and technology can be applied in the professional institutions, further training and retraining centers in the process of core curriculum drafting, additional vocational programs and working programs as well.
\end{abstract}

Keywords: modular competence-based curriculum, the learning outcome, competences, the principles of curriculum designing, the technology of the program implementation

\section{Introduction}

In current conditions there is the need in the system of higher education that would provide the possibility of building an individual educational and vocational course, equal opportunities for social, academic, professional and territorial mobility of the students. The most appropriate organization of the vocational education in this context becomes a modular structure on the basis of the competence approach.

The main reason of the growing interest about the modular competence-based approach lies in the fact that vocational education in contemporary world hardly meets the needs of an individual and society from the point of social and personal identity, professional flexibility, the requirements of the modern labor market, which primarily indicates its quality performance (Mukhametzyanova et al., 2007; Masalimova et al., 2014).

The existing curricula are unable to: a) ensure that the bachelors' and masters' training meets the requirements of the labor market; b) carry out the transition to the learning process based on competencies formation; c) arrange for developing the individual learning ways for every student in a flexible educational structure taking into consideration his interests, needs and characteristics.

One of the key instruments of the modular competence-based education is modular competence-based curricula. The modular competence-based curriculum we define as a complex and sequence of the modules that are aimed at acquiring specific competencies needed for earning a particular degree within a specific qualification to effectively carry out professional activities and promote personal and social development of the students (Sakhieva, 2012).

The foundation of the modular competence-based curriculum structure and technology of implementation is based on the modular competence-based approach, the conceptual idea of which is to focus not on the curriculum, but on the 'learning outcomes'-the expected performance of what a student should know, understand and be able to perform at the end of his training course to meet the employment requirements. The learning outcomes are stated in a number of competencies-the exact and clear list of what a student should know, 
understand and be able to apply after the termination of the learning process, in the course of his professional and social activities. The reporting system of the learning complexity is the credit units (Bulletin of Education, 2004).

The introduction of modular competency-based curricula will minimize the shortcomings of the existing students' training such as: focusing on obtaining a profession in general but not carrying out particular activities; inflexibility of the vocational training in respect to the modern requirements of the employment market; lack of consideration of the individual characteristics, educational needs and students' experience.

\section{Case-studies}

Since the middle of the XX century there has been systematic research regarding modularity in education (Gulchevskaya, 2003; Choshanov, 1996). The researchers in their works of the modular education have focused on the various problems of its use in the educational process. For example, P.A. Yutsyavichene and his disciples studied modular education through the prism of creating the most favorable conditions for personality development (Yutsyavichene, 1989). C. Curch, focused attention on the possibility of self-study by means of corrective modules (Curch, 1975). M. Goldshmid, J. Russell paid special attention to the opportunities of studying at your own pace, using an individual way of learning, skills formation (Goldshmid \& Goldshmid, 1972; Russell, 1974). S. Ya. Batyshev, V. P. Bespalko, M. V. Klarin, G. K. Selevko, N. E. Erganova have made emphasis on the problem of modular technology of the education activities (Batyshev, 1997; Bespalko, 1995; Klarin, 1994; Selevko, 1998; Borodina \& Erganova, 1994).

Numerous studies have dealt with the theory and practice of implementation of the competence-based approach in professional education (Baidenko, 2005; Bolotov, 2003; Zeer \& Symanok, 2005; Zymnyaya, 2006; Ibragimov, 2003).

A number of modern studies has been devoted to building modular curricula based on the competence approach (Muraveva et al., 2005; Oleinikova et al., 2005).

At the same time the questions connected with designing the modular competence-based curricula, the technology of their implementation into higher education are still underexplored.

In order to explore the experience of using modular competence-based curricula in higher education and due to the keen interest to the problem a group of teachers were surveyed. The results of the survey showed that: $57 \%$ of the surveyed teachers had no experience in structuring and using modular competence-based curriculum in the modern sense; the majority of teachers $(89 \%)$ would like to receive the detailed information about the structure of modular competence-based education programs, projecting technology, organizational and pedagogical conditions of their application in the professional education process; $68 \%$ respondents would like to use modular competence-based curriculum and $61.3 \%$ of them declared that the implementation process should be gradual and should be provided with scientific, methodological, organizational and technological means.

\section{Results and Discussions}

\subsection{The Principles of Curriculum Designing}

Drafting modular competence-based curricula is based on the principles of modular education and on the main ideas of the competence approach. However, it seems reasonable to expand and summarize some of the principles for their practical application.

The design basis of the modular competence-based curricula comprises the following principles:

- the principle of modularity that specifies the structuring of the curriculum at all levels (using the modules as the main means of mastering educational information block about the proposed professional activity by the students and exact structuring of the module as an embodiment of curriculum consisting of complete content-related teaching elements);

- the principle of integrity. Firstly, it assumes integrative purposes; Secondly, integrative modules themselves; Thirdly, integrative program itself (a combination of comprehensive, integrating and particular didactic tasks on the basis of their hierarchy, integrity of the modules and their training elements including interdisciplinary connections, as well as the ability of the modular competence-based curriculum to integrate into any curriculum);

- the flexibility principle which includes structural flexibility, curriculum flexibility, technological flexibility, the control system flexibility (structural flexibility: flexibility of particular modules and overall program, which allows to structure various programs on the basis of its constituents following the program customers' needs; content flexibility: the ability to quickly and tirelessly change or update the content of each element of the 
module in terms of the ongoing integration processes and socio-economic dynamics, to adapt to the changing conditions of professional activity, individual abilities and needs of the students; that is possible due to an invariant kernel in the process of education curriculum construction and its replaceable peripherals; technological flexibility: variability of methods, forms and means of training; monitoring and evaluation systems flexibility: providing the procedural educational aspects in the complex of efficiency);

- the principle of structural integrity of the content that defines the complexity and integrity of the target, substantive and technological components of the curriculum, its theoretical and applied aspects of training also providing interrelated thematic integrity of the curriculum within the syllabus (the unity in one organizational and methodological structure: a) general and didactic purposes of logically accomplished educational unit, methodological guidance and control systems; b) substantive (autonomous subject units forming an interconnected thematic integrity within the program, thus building cohesive curriculum), organizational, methodological and technological components; c) theoretical and applied aspects);

- the principle of targeting at learning outcomes-(target, substantive, technological components of the program should be focused on achieving 'learning outcomes' by the students, which are expressed in the number of competencies required for professional activity and promoting personal and social development of the students).

\subsection{The Structure of the Modular Competence-based Curriculum}

We have developed a structure of modular competence-based curriculum which includes three sections:

\subsubsection{The Objectives and General Description of the Curriculum}

This section includes the following elements:

- the explanatory summary of the program, serving as a guidance, describes its application, actuality and importance in the process of studying for Bachelor/Master, its subject (as a reference point while formulating educational goals), the continuity, the discipline place in the structure of the core curriculum, its interdisciplinary and intradisciplinary connections, fundamental differences of the modular competence-based approach in building curriculum in general, and the its structure in particular;

- the indication of the term;

- the requisite time distribution of the curriculum is indicated in academic hours/credit units;

- the requisite distribution of the students' time, which determines the classroom and individual hours;

- the forms of final control-test/exam;

- the program objectives represent the number of competencies that the students will acquire at the end of their studies (the competencies, first and foremost, should be clearly defined and intended for practical use, shaping students' personal qualities; secondly, they should be activity oriented and record the intended changes in the way of the students' activities; third, they should be related to the learning outcomes; fourth they should perform a diagnostic function).

\subsubsection{The Content and Methodological Support of the Modules Included into the Curriculum.}

This Section includes:

- the methodological guidelines for the teachers to organize teaching process within the program;

- the methodological guidance for the students concerning modules study, conducting classroom and extracurricular work indicating a list of recommended course books, with the rationale for their choice, specifying the basic and optional literature within the curriculum as a whole;

- the summary of the program;

- the list and order of the modules (submodules) study, their objectives (focused on the implementation of the ultimate goals of the curriculum), the content which is marked with the organizational teaching forms (lecture, seminar, extracurricular (individual) work, etc.) in the course of which it will be studied, and their volume (for full-time, part-time, distant and other forms of education);

- a complex of modern technologies and interactive teaching methods that encourage molding the competencies for each separate module (submodule);

- the complex of the teaching methods applied;

- the list of competencies, specific actions which are generated in the course of studying the modules (submodules); 
- the list of criteria indexes of competencies formation;

- the means of modular and intra- modular control;

- the basic (2-3 sources) and further reading for every module (submodule).

\subsubsection{The Expected Learning Outcomes and Final Control and Assessment Tools}

This section includes the following components:

- the expected learning outcomes that include specific actions based on particular issues of the Federal State Educational standards and professional standards that the students will achieve at the end of the program study, and that will contribute to their professional employability at the market, personal and social self-realization (firstly, they should be coordinated with each other and not go beyond the intended objectives; and secondly, while choosing a complex of learning outcomes, it is advisable to check the value of any of them to form a competence and the ability to achieve it within this module);

- the criterial indicators of competencies formation on the basis of the program study (while developing the criteria it is necessary to ensure that only the specified activities inherent in the learning outcomes are assigned, are recommended from 4 to 6 criteria for every learning outcome);

- the total of the final assessment tools to determine the final level of the curriculum learning outcomes (evaluation of every learning outcome in the total assessment procedure is performed separately; the overall final grade is determined as the average of the grades obtained from separate results, but it is important to point out that in some cases the complex grade is given; during evaluation it is reasonable to use such methods as simulation, project method, portfolio, peer review method and others).

While describing the structure of modular competence-based curriculum, special attention has been paid to its three components, namely: objectives, learning outcomes and criteria indicators of competencies formation, as these components are essential, strategic components of the modular competence-based education programs and particularly their design distinguish such programs from traditional ones.

\subsection{The Technology of Implementation of Modular Competence-based Education Programs into Higher} Professional Institutions

The objective of the introduction of the modular competence-based education programs is improving the quality of the professional education.

The implementation tasks: 1) to ensure that the students' professional training satisfies current and perspective employment market requirements, 2) the transition to education through the development of competencies, 3) actualization of the possibility of building individual learning paths for any student inside a flexible educational structure that takes into account their interests, needs and characteristics.

\section{The stages of implementation of modular competence-based training programs in higher professional} education:

I stage. The stage of motives-and-needs involves realizing the motives and needs of introduction of modular competence-based curriculum in the educational process of higher education.

II Stage. Analytical and preparatory stage comprises a comprehensive analysis and preparation of the introduction of the modular competence-based education programs into the higher educational process and consists of several sub-stages: 1) the analysis of the legal documents and other materials to implement the theoretical modular competence-based education programs into the educational process of the higher education institutions, both domestic and foreign; 2) the analysis of domestic and foreign experience of introducing modular competence-based curriculum in the higher education process; 3 ) the opinion surveys within academic teaching community and students on topical issues of the modular competence-based curriculum implementation in the process of vocational education; 4) the choice of pilot sites for the implementation of modular competence-based curriculum; 5) logistics, informative and publishing support of the implementation process of the modular competence-based curriculum in the educational professional process; 6) identification of the organizational and pedagogical conditions for the efficient implementing of the modular competence-based curriculum in the learning process of higher schools; 7) the criteria and criterial idetificators development of the implementation of the modular competence-based curriculum in the professional schools educational process.

Stage III. Adaptive-innovative stage has to adapt and implement modular competence-based curriculum in the educational process of higher education institutions. It consists of several sub-steps: 1) the adaptation of the existing domestic and foreign experience of introducing modular competence-based curriculum in the 
educational process of vocational school taking into account the peculiarities and traditions of our education system and particular educational institutions; 2) organization and arranging scientific conferences, seminars, round tables, workshops for practical experience exchange in implementing modular competence-based curriculum in the educational process of higher vocational schools, presentation and explanation of the experience; 3 ) the actual implementation of modular competence-based curriculum in the educational process of vocational educational institutions which are non-experimental pilot sites in this issue.

Stage $I V$. Evaluative stage is to assess the results of the experimental implementation of modular competence-based curriculum in the educational process of professional schools, it consists of several sub-steps: 1) Assessment of the effectiveness of the modular competence-based curriculum implementation by experimental sites in terms of the developed criteria and criteria indicators; 2) providing expert assessment of an experimental implementation of modular competence-based curriculum in educational schools, which are experimental sites.

Stage $V$. Reflexive correction stage representing the reflection and adjusting the process of implementing modular competence-based education programs in the educational process of higher school on the basis of professional review and implementation practice consisting of several sub-steps: 1) to introduce appropriate adjustments in the process of implementing modular competence-based curriculum in the educational process of professional educational institutions on the basis of expert evaluations; 2) spreading the experience of modular competence-based curriculum implementation in the professional educational process; 3) to create practical recommendations for the implementation of modular competence-based curriculum into broad practice.

The restructuring of the educational process according the principles of modularity in practical terms require preliminary thorough interdisciplinary study of the existing curricular in order to eliminate fragments duplication in the academic disciplines; determination of the training modules list; the development of scientific and methodological support of the training modules implementation that will require additional efforts of the academic teaching staff, renovation of the material and technical, informative and publishing resources; implementation of managerial and administrative activity on the new principles meeting modern restructuring of the educational process.

Further research should focus on identification of not only the benefits of the introduction of modular competence-based curriculum, but also the possible risks of their introduction in the educational process of vocational schools, as well as possible ways to minimize them. Relevant in this context is the problem of identifying the conditions of effectiveness of the implementation of these programs in the educational process of higher education and the development of methodological guidelines at the level of goal-setting, curriculum, educational process: at the level of the learning outcomes and assessment criteria.

\section{Conclusion}

Thus, the development and implementation of the educational process of modular competence-based curriculum into higher education is one of the effective means of professional competence formation. The introduction of modular competence-based curricula in higher professional institutions provide the student with an opportunity to acquire education with due regard to specific educational goals, cognitive peculiarities, the awareness and demands levels; the teacher with the extra time for individual and group counseling; the school and professional education in general with the opportunity to train students in accordance with the current requirements of the employment market. In this regard, the introduction of modular competence-based curriculum in higher education will help to improve the quality of professional education in general, and will perform itself as one of the priorities of the vocational education reformation.

The results of this article may be recommended for researchers; teachers of professional institutions, teachers and supervisors of vocational and further training institutions in the development of modular competence-based curricula.

\section{Acknowledgements}

The authors thank all participants in this study for their kind cooperation.

\section{References}

Baidenko, V. I. (2005). Competence-based approach to the design of the state educational standards of higher education, Resource guide (p. 114). Moscow, Research Center of the specialist training quality.

Batyshev, S. Y. (1997). Modular education (p. 307). Moscow.

Bespalko, V. P. (1995). Pedagogy and innovative learning technologies (p. 336). Moscow, The Institute of 
Vocational Education.

Bolotov, V. A. (2003). A competence model: From idea to the curriculum. Pedagogy, 10, 8-14.

Borodina, N. V., \& Erganova, N. E. (1994). The basis for the development of modular training technology: Textbook (p. 290). Ekaterinburg, Ural State University of Professional Education Publishing.

Bulletin of Education. (2004). The model regulation of the educational process organization in higher education institution, using a credit system: Annex to the letter of the Russian Ministry of March 9, №15-55-357in.

Choshanov, M. A. (1996). A flexible technology of problem-modular training (p. 160). Moscow: Public education.

Curch, C. (1975). Modular Courses in British Higher Education. A critical assessment in Higher Education Bulletin, 3.

Goldshmid, B., \& Goldshmid, M. L. (1972). Modular Instruction in Higher Education. Higher Education, 2.

Gulchevskaya, V. G. (2003). The technology of modular education: The problem of introducing the experience of the national school into widespread application. Retrieved from http://www.ipkpro.aaanet.ru

Ibragimov, G. I. (2003). Competence-based approach in professional education. Scientific background of a competent specialist formation in the system of continuous professional education. The materials of the national Russian scientific practical conference, 97-108. Kazan.

Klarin, M. V. (1994). Innovative models of education in the international pedagogic research (p. 224). Moscow.

Masalimova, A. R., Zakirova, V. G., Chernova, Y. A., Drovnikov, A. S., Shaidullina, A. R., \& Sakhieva, R. G. (2014). Structure and Content of Mentors Psychological and Pedagogical Training Curriculum. Life Science Journal, 11(7s), 381-386.

Mukhametzyanova, G. V., Mukhametzyanov, I. S., Gilmanov, A. Z., \& Panchenko, O. (2007). Modernization of the education quality in higher school: The experience of the study (based on the materials of the Academy of Social Education) (p. 304). Kazan: Kazan State University Publishing.

Muraveva, A. A., Kuznetsova, N., \& Chervyakova, T. N. (2005). Organization of modular training based on competencies, A Manual for Teachers (p. 307). Moscow:.

Oleinikova, O. N., Muraveva, A. A., Konovalov, J., \& Sartakova, E. V. (2005). The development of modular programs based on competences (p. 288). Textbook, Moscow.

Russell, J. D. (1974). Modular Instruction. Minneapolis, Minn.: Burgest Publishing Co.

Sakhieva, R. G. (2012). Module-competency training programs in higher vocational school. Kazan Pedagogical Journal, 5-6, 14-20.

Selevko, G. K. (1998). Modern educational technologies (p. 256). Moscow, Public education.

Yutsyavichene, P. A. (1989). Theory and practice of modular education (p. 271). Kaunas.

Zeer, E., \& Symanok, E. (2005). Competence-based approach. What is its place in vocational education modernization? (Theoretical and methodological approach). Higher education in Russia, 4, 13-15.

Zymnyaya, I. A. (2006). Competence-based approach. What is its place in the modern approaches to education? (Theoretical and methodological approach). Higher education today, 8, 20-26.

\section{Copyrights}

Copyright for this article is retained by the author(s), with first publication rights granted to the journal.

This is an open-access article distributed under the terms and conditions of the Creative Commons Attribution license (http://creativecommons.org/licenses/by/3.0/). 